\title{
A progressão em textos argumentativos escritos: uma análise da progressão referencial em produções de um aluno do Ensino Básico
}

\section{The progression in written argumentative texts: an analysis of the referential progression in productions of a student in Basic Education*}

\author{
Paola Tassinari Groos ${ }^{* *}$ \\ Universidade Federal de Santa Maria, Santa Maria, RS, Brasil \\ Gil Roberto Costa Negreiros ${ }^{* * *}$ \\ Universidade Federal de Santa Maria, Santa Maria, RS, Brasil
}

\begin{abstract}
Resumo: O tema deste artigo é a progressão textual em textos escritos produzidos no contexto da Educação Básica. Objetiva-se investigar, por meio da metodologia da pesquisa-ação, o processo de qualificação da produção textual de um aluno da Educação Básica, com foco na progressão textual, mais especificamente a progressão referencial. O corpus constitui-se de textos escritos por alunos, coletados em oficinas de língua portuguesa desenvolvidas em uma escola pública de Santa Maria - RS. A sustentação teórica está baseada na interação verbal, defendida por Bakhtin (1997; 2014); e na perspectiva da Linguística Textual. Serão analisadas três redações que compõem o corpus da dissertação $A$ qualificação da progressão textual em oficinas de producão de texto. Os resultados revelam que, com o decorrer das oficinas de produção de texto, avanços significativos em relação à progressão referencial foram alcançados.
\end{abstract}

Palavras-chave: Linguística textual. Progressão textual. Progressão referencial. Pesquisa-ação. Interação.

\begin{abstract}
The theme of this paper is the textual progression in written texts produced in the context of Basic Education. The aim in this study is to investigate, under the action-research methodology, the process of qualification in textual production of a Basic Education student, focusing on textual progression, more specifically, on the referential progression. The corpus consists of texts written by students, collected in Portuguese language workshops developed in a public school in Santa Maria - RS. The theoretical support is based on the verbal interaction, defended by Bakhtin (1997; 2014); and from the perspective of Textual Linguistics. Three written texts will be analyzed as the corpus in the dissertation A qualificação da progressão textual em oficinas de produção de texto. The results show that, in the course
\end{abstract}

\footnotetext{
* Este artigo é um recorte teórico, metodológico e analítico da dissertação de mestrado intitulada $A$ qualificação da progressão textual em oficinas de produção de texto, de autoria de Paola Tassinari Groos, desenvolvida sob orientação do Prof. Dr. Gil Roberto Costa Negreiros, e defendida em 2017, no Programa de Pós-graduação em Letras da Universidade Federal de Santa Maria. Ademais, o presente trabalho foi realizado com apoio da Coordenação de Aperfeiçoamento de Pessoal de Nível Superior - Brasil (CAPES) - Código de Financiamento 001.

** Doutoranda em Estudos linguísticos no Programa de Pós-graduação em Letras, Universidade Federal de Santa Maria, Santa Maria, RS, Brasil; paola_groos@yahoo.com.br

*** Professor adjunto do Departamento de Letras Vernáculas da Universidade Federal de Santa Maria, Santa Maria, RS, Brasil; gil.negreiros@ufsm.br
} 
of the text production workshops, significant advances regarding referential progression were achieved.

Keywords: Textual linguistics. Textual progression. Referential progression. Action research. Interaction.

\section{CONSIDERAÇÕES INICIAIS}

Um dos maiores desafios para os estudos do texto e do discurso, segundo Bentes, Ramos e Alves Filho (2010, p. 390), está relacionado à visibilidade das relações entre as pequeninas partes (os 'dados' locais) e o todo no qual essas partes se inserem. Este trabalho se insere nessa relação, ao propor, como objetivo, investigar, por meio da metodologia da pesquisa-ação, o processo de qualificação da produção textual de um aluno da Educação Básica, com foco na progressão textual, mais especificamente a progressão referencial. Para isso, três redações que compõem o corpus serão analisadas - referentes à produção de tal aluno: o primeiro, o terceiro e o último texto produzidos nas oficinas. A hipótese de nossa pesquisa é a de que, ao qualificarmos a progressão textual, conseguimos alcançar um processo maior: a relação entre a produção interacional do texto e os arranjos locais da escrita.

O que justificou o desenvolvimento do estudo citado foi o interesse em amenizar dificuldades relacionadas à progressão textual, percebidas durante nossa atuação acadêmica, em projetos de extensão que possuíam atividades que envolviam a produção de textos. Além disso, é fundamental pesquisar sobre os avanços que podemos realizar para o ensino de produção textual não só para a formação de futuros profissionais da área de Letras, como também para a aprendizagem dos discentes da Educação Básica.

A metodologia utilizada para a realização da pesquisa foi a pesquisa-ação, embasada em Thiollent (1996) e Tripp (2005), visto que possibilita a interação entre o pesquisador e os sujeitos da pesquisa. Além disso, através da pesquisa-ação, o pesquisador pode desempenhar papel ativo na realidade observada, o que se enquadra com a perspectiva do professor como profissional reflexivo, proposta por Perrenoud (2002), e mediador do conhecimento. A pesquisa foi desenvolvida em diferentes momentos: oficinas de produção textual para investigação do processo de escrita dos alunos e, depois da escolha do sujeito de pesquisa, com base no desenvolvimento de seus textos, análise desses textos conforme critérios de investigação ${ }^{1}$.

Ministramos treze oficinas de produção textual, realizadas uma vez por semana em uma Escola Estadual do município de Santa Maria (RS, Brasil), entre os meses de setembro e dezembro de 2016. Os 12 alunos envolvidos na pesquisa frequentavam o $2^{\circ}$ ano do Ensino Médio e participaram de maneira voluntária, no turno vespertino, inverso ao das disciplinas obrigatórias ${ }^{2}$.

\footnotetext{
${ }^{1}$ A pesquisa está registrada no Comitê de Ética em Pesquisa (CEP) sob o número 1.544.460, com Certificado de Apresentação para Apreciação Ética (CAAE) número 55495616.0.0000.5346. Por questões éticas, não serão mencionados os nomes do sujeito da pesquisa e da escola de Educação Básica em que as oficinas de produção de texto foram realizadas.

2 Para a escolha do sujeito de pesquisa, foram adotados dois critérios: o número de presenças do estudante nas oficinas, pois, assim, o número de textos pertencentes ao corpus seria maior, assim como o desempenho qualitativo nas produções textuais.
} 
O aporte teórico primordial da referida pesquisa ancorou-se: na interação verbal, proposta por Bakhtin (1997; 2014); no interacionismo social, defendido por Vygotsky (1984; 1991); e na perspectiva da Linguística Textual, cujos representantes são, por exemplo, Charolles (1978), Beaugrande e Dressler (1983), Koch (2014; 2015) e Koch e Elias (2016). Na próxima seção, discutiremos parte de tal referencial teórico, relevante para a análise do corpus citado.

\section{ALGUNS ASPECTOS SOBRE A PERSPECTIVA INTERACIONISTA DE LINGUAGEM E O CONCEITO DE TEXTO}

Em relação à perspectiva interacionista de linguagem adotada na pesquisa, ressalta-se que Bakhtin (2014, p. 117) defende que a palavra é composta por duas faces, "ela é determinada tanto pelo fato de que procede de alguém, como pelo fato de que se dirige para alguém. Ela constitui justamente o produto da interação do locutor e do ouvinte" (grifos do autor). Para nós, que na pesquisa trabalhamos com o ensino de Língua Portuguesa, mais especificamente com leitura e produção textual, foi primordial considerar a interação entre professora/pesquisadora e alunos como parte constituinte do processo de aprendizagem.

Já que estamos tratando de interação, é fundamental destacarmos a percepção que temos dos sujeitos interactantes, visto que "a língua existe porque os sujeitos a produzem" (Micarello; Magalhães, 2014, p. 156). Ademais, o trabalho com leitura e escrita na escola também exige que demonstremos que, nas atividades que envolvem linguagem, devemos considerar os indivíduos envolvidos. Bakhtin (1993) considera que cada sujeito é único. Para o teórico, "aquilo que pode ser feito por mim não pode nunca ser feito por ninguém mais. A unicidade ou singularidade do Ser presente é forçadamente obrigatória" (Bakhtin, 1993, p. 58).

Essa noção de sujeito único foi extremamente importante para a pesquisa, pois, durante a realização das oficinas, cada aluno apresentou desenvolvimento de escrita singular. Com isso, coube à professora/pesquisadora perceber e acompanhar tal desenvolvimento.

Isso posto, já que utilizamos a concepção interacionista da língua, concordamos com Koch (2014, p. 173), ao afirmar que "o texto passa a ser considerado o próprio lugar da interação e os interlocutores, como sujeitos ativos que dialogicamente - nele se constroem e são construídos" (grifos da autora). Ademais, como defende a linguista,

é preciso pensar o texto como lugar de constituição e de interação de sujeitos sociais, como um evento, portanto, em que, conforme Beaugrande (1981), convergem ações linguísticas, cognitivas e sociais, ações por meio das quais se constroem interativamente os objetos de discurso e as múltiplas propostas de sentidos, como função de escolhas operadas pelos coenunciadores, entre as inumeráveis possibilidades de organização textual que cada língua lhes oferece [...] (Ibid., p. 173).

Então, é através do texto que há interação e mobilização de diferentes estratégias, sejam elas de ordem sociocognitiva, interacional ou textual, a fim de que o sentido seja produzido. Dessa forma, o texto é o resultado de atividades verbais de indivíduos atuantes em sociedade. 


\section{A PROGRESSÃo TEXTUAL: COESÃO E COERÊNCIA EM FOCO}

Como estamos interessados no material conceitual e linguístico que faz o texto progredir, deter-nos-emos nos estudos relativos à coesão e à coerência e, em seguida, trataremos da progressão referencial.

A coesão, segundo Koch (1997, p. 35), é "o fenômeno que diz respeito ao modo como os elementos linguísticos presentes na superfície textual encontram-se interligados, por meio de recursos também linguísticos, formando sequências veiculadoras de sentido". Dentre as grandes modalidades desse critério de textualidade, estão a coesão referencial, em que um componente da superfície textual faz remissão a outro elemento do texto, e a coesão sequencial. Esta última também pode ser chamada de progressão textual e é o foco de nossa pesquisa. Para Koch (2006),

\footnotetext{
a progressão textual (sequenciação) diz respeito aos procedimentos linguísticos por meio dos quais se estabelecem, entre segmentos, do texto (enunciados, partes de enunciados, parágrafos e mesmo sequências textuais), diversos tipos de relações semânticas e/ou pragmáticodiscursivas, à medida que se faz o texto progredir (Koch, 2006, p. 121).
}

Assim, é através da progressão textual que o texto avança nas ideias e nos argumentos, por exemplo. Segundo a autora citada acima, essa progressão pode realizar-se com atividades formulativas em que o produtor introduz no texto recorrências de diversos tipos, tais como "reiteração de itens lexicais, paralelismos, paráfrases, recorrência de elementos fonológicos, de tempos verbais etc.” (Koch, 2006, p. 121).

Entretanto, a progressão de um texto também está atrelada fortemente à coerência, que "diz respeito ao modo como os elementos subjacentes à superfície textual vêm a constituir, na mente dos interlocutores, uma configuração veiculadora de sentidos" (Koch, 1997, p. 41). Desse modo, como afirma Koch (2009),

\footnotetext{
a relação da coesão com a coerência existe porque a coerência é estabelecida a partir da sequência linguística que constitui o texto, isto é, os elementos da superfície linguística é que servem de pistas, de ponto de partida para o estabelecimento da coerência. A coesão ajuda a estabelecer a coerência na interpretação dos textos, porque surge como uma manifestação superficial da coerência no processo de produção desses mesmos textos [...] (Koch, 2009, p. 49).
}

Passemos, então, ao conceito de referenciação, ou seja, "as diversas formas de introdução, no texto, de novas entidades ou referentes" (Koch; Elias, 2008, p. 123). A referenciação, como defende Koch (2003, p. 79), "constitui uma atividade discursiva, pressuposto esse que implica uma visão não-referencial da língua e da linguagem”. Por isso, adota-se, atualmente, referenciação e não mais referência, pois o primeiro termo abarca a construção e a reconstrução no interior do discurso, a visão de mundo e as crenças individuais (cf. Koch; Elias, 2008).

A progressão referencial ocorre quando os referentes são reativados ou introduzem outros referentes e diz respeito aos procedimentos linguísticos por meio dos quais se estabelecem, entre os segmentos do texto (enunciados, partes de enunciados, parágrafos e sequências maiores do texto), diversos tipos de relações 
semânticas e/ou pragmáticas, à medida que se faz o texto progredir (Koch; Elias, 2016, p. 100).

Durante a construção de um texto, Koch (2003) apresenta os seguintes princípios de referenciação: ativação, reativação e de-ativação. Na ativação, o referente, que ainda não foi mencionado, é introduzido. Na reativação, um referente já presente no texto é novamente ativado e, na de-ativação, esse referente é desativado, pois outro foi introduzido.

Esse tipo de progressão, segundo a linguista, é realizado com recorrência de termos e pode ocorrer com as seguintes estratégias: uso de pronomes ou elipses, uso de expressões nominais definidas e uso de expressões nominais indefinidas. A primeira estratégia, uso de pronomes ou elipses, envolve "as formas gramaticais que exercem a 'função pronome' (pronomes propriamente ditos, numerais, advérbios pronominais)" (Ibid., p. 85-86). Na segunda estratégia, ou seja, no uso de expressões nominais definidas, "as formas linguísticas são constituídas, minimamente, de um determinante (artigo definido ou pronome demonstrativo), seguido de nome" (Ibid., p. 86-87). No uso de expressões nominais indefinais, terceira estratégia, "a função é anafórica (e não, como é mais característico, de introdução de novos referentes" (Ibid., p. 88). Koch (2014) afirma que, além de garantir a progressão referencial, tais estratégias garantem a orientação dos argumentos do texto e, também, o sentido.

As formas nominais referenciais assumem muitas funções em textos. Koch e Elias (2016) elencam cinco funções: categorizar e recategorizar o referente; apresentar e reapresentar o referente à medida que o texto avança; resumir ou encapsular porções textuais dando-lhes um rótulo; marcar o parágrafo; e orientar argumentativamente num dado sentido. Em nossa análise, demarcaremos essas cinco funções.

\section{A METOdologia dA PESQUISA-AÇÃO E SUA CONTRIBUIÇÃo PARA O ESTUdO PROCESSUAL DE ASPECTOS TEXTUAIS}

A metodologia adotada para a realização da pesquisa foi ancorada na pesquisaação, que tem como representantes, por exemplo, Thiollent (1996) e Tripp (2005). Esse método pode ser utilizado por diferentes campos de atuação, segundo Tripp (2005), tais como administração, agricultura, educação e saúde. Na área educacional, "a pesquisa-ação é uma estratégia para o desenvolvimento de professores e pesquisadores de modo que eles possam utilizar suas pesquisas para aprimorar seu ensino e, em decorrência, o aprendizado de seus alunos" (Tripp, 2005, p. 445).

Thiollent (1996) acrescenta que tal metodologia possibilita a interação entre o pesquisador e os sujeitos da pesquisa. Segundo o autor, um dos objetivos dessa modalidade de pesquisa é oferecer aos sujeitos envolvidos subsídios para a transformação de sua realidade, pois amplia a compreensão sobre características, potencialidades ou necessidades existentes no meio. Como favorece maior clareza sobre peculiaridades envolvendo processo e resultados, permite que o investimento em avanços tenha maior probabilidade de sucesso. De acordo com o teórico, a pesquisa-ação

é um tipo de pesquisa social com base empírica que é concebida e realizada em estreita associação com uma ação ou com a resolução de um problema coletivo e no qual os pesquisadores e os participantes representativos da 
situação ou do problema estão envolvidos de modo cooperativo ou participativo (Thiollent, 1996, p. 14).

Tripp (2005, p. 447) ainda afirma que esse método "é uma forma de investigação-ação que utiliza técnicas de pesquisa consagradas para informar a ação que se decide tomar para melhorar a prática". Cabe-nos salientar, conforme destaca o referido autor, que a pesquisa-ação tem grande distinção da pesquisa científica tradicional, pois, ao mesmo tempo em que altera o que é pesquisado, é limitada pela ética da prática e pelo contexto investigado. Assim, essa metodologia "requer ação tanto nas áreas da prática quanto da pesquisa, de modo que, em maior ou menor medida, terá características tanto da prática rotineira quanto da pesquisa científica" (Tripp, op. cit.).

\subsection{O planejamento das oficinas de produção de texto}

O planejamento das oficinas, seguindo a metodologia da pesquisa-ação, está apoiado tanto no ciclo desse método quanto no ciclo da investigação-ação. Desse modo, apresentaremos, neste item, o ciclo adaptado na realização das oficinas de produção textual. Essa adaptação envolveu, por exemplo, investigação inicial nos textos dos voluntários, seleção dos materiais didáticos, avaliação das produções, reescritas e novas produções textuais. Em primeiro lugar, demonstramos esse ciclo, através do diagrama na Figura 1.

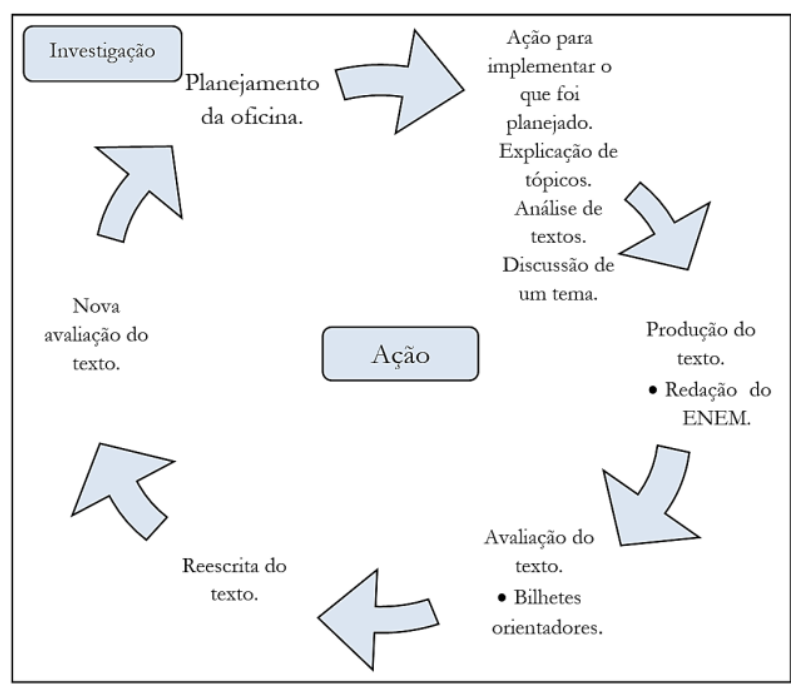

Fonte: Tripp (2005, p. 446). Adaptado.

Figura 1 - Ciclo das oficinas de produção textual.

Para podermos desenvolver os objetivos da pesquisa, iniciamos as oficinas com a investigação diagnóstica nos textos dos alunos. Solicitamos que produzissem um texto dissertativo-argumentativo sobre determinado tema. Avaliamos tais produções e, a partir disso, planejamos a segunda oficina. O aporte teórico para preparar o material didático sustentou-se na Linguística Textual.

Nessa segunda oficina, houve a explicação de tópicos relacionados às dificuldades percebidas a partir da produção diagnóstica e da discussão de um tema que seria o foco da produção textual de tal oficina. Solicitamos, então, que os alunos 
produzissem um texto dissertativo-argumentativo, nos moldes da redação do ENEM. Encerrada a oficina, avaliamos essas produções, com base nos critérios do ENEM, e produzimos bilhetes orientadores ${ }^{3}$ sobre aspectos textuais relevantes. Além disso, planejamos tópicos que iríamos explicar na próxima oficina.

$\mathrm{Na}$ oficina seguinte, em primeiro lugar, entregamos as produções com os bilhetes orientadores. Depois, explicamos determinados conteúdos, relacionados ao que havíamos avaliado nas produções. Por último, solicitamos que os alunos reescrevessem seus textos.

Então, realizamos uma nova avaliação dos textos, a partir da reescrita, para verificarmos o progresso alcançado. Diante dessa segunda avaliação, planejamos uma nova oficina, em que outros tópicos seriam explicados e discutidos e uma nova produção, com outro tema, seria solicitada. Assim, repetimos o ciclo das oficinas, ilustrado na Figura 1.

\section{ANÁLISE DO DESENVOLVIMENTO DA PROGRESSÃO REFERENCIAL EM DISSERTAÇÕES ARGUMENTATIVAS}

Antes de partirmos para a análise do corpus, é necessário que detalhemos os critérios específicos para o levantamento e para a avaliação do desenvolvimento da progressão textual nos textos. $\mathrm{O}$ quadro a seguir ilustra isso.

Quadro 1- Critérios para análise do corpus da dissertação.

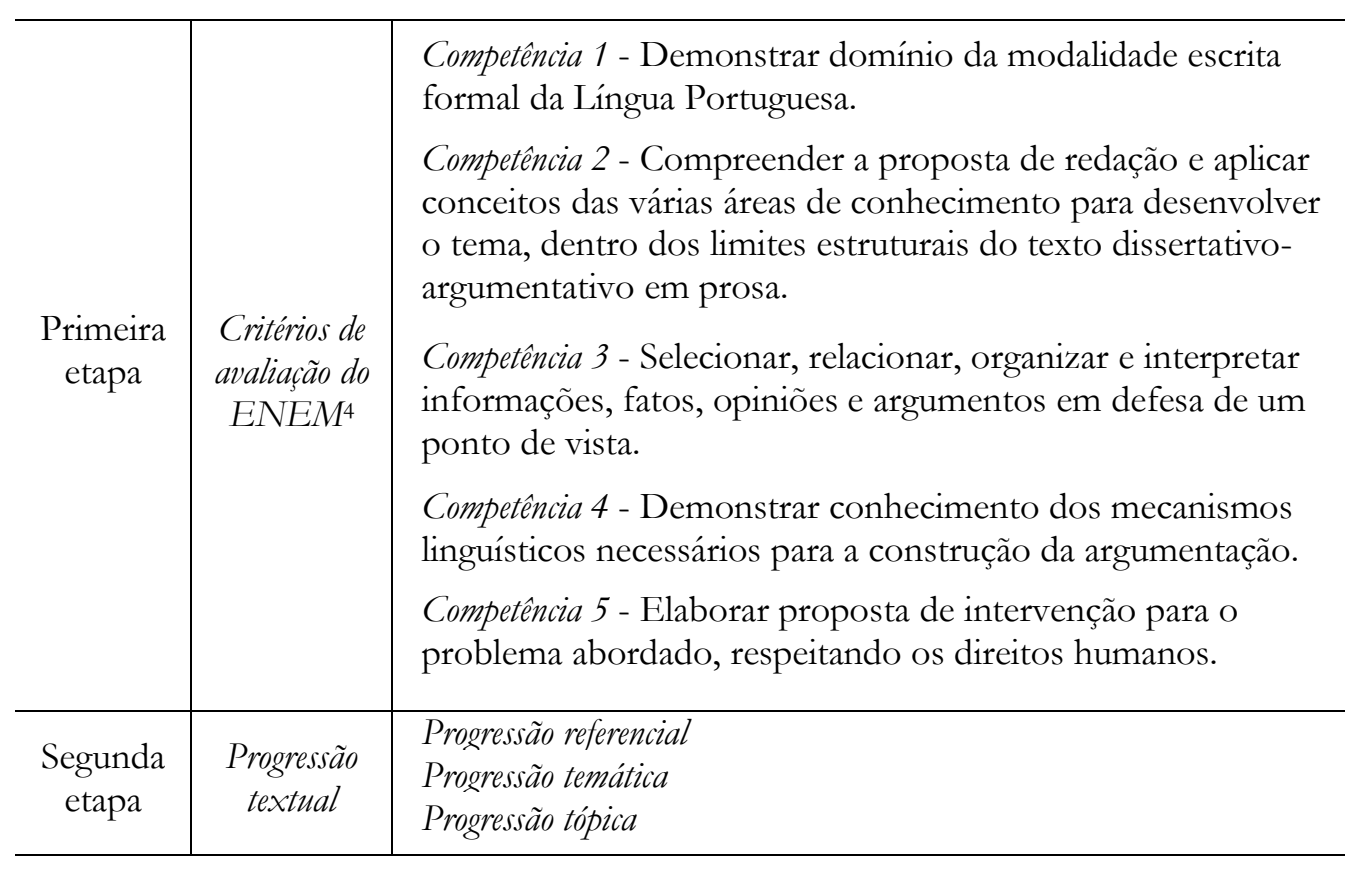

\footnotetext{
${ }^{3}$ O bilhete orientador, como destaca Fuzer (2012), é uma das formas que os professores de Língua Portuguesa encontram para dialogar com os textos dos alunos e com os próprios alunos. Além disso, como aponta Ruiz (2001, p. 63), “os 'bilhetes', em geral, têm duas funções básicas: falar acerca da tarefa de revisão pelo aluno ou falar, metadiscursivamente, acerca da própria tarefa de correção pelo professor".

${ }^{4}$ Critérios de avaliação retirados de Brasil (2013): A redação do Enem 2013: guia do participante.
} 
Os textos serão analisados em duas etapas. Em primeiro lugar, trataremos das cinco competências exigidas no ENEM. Em segundo, analisaremos a progressão textual, com foco na progressão referencial.

\begin{tabular}{|c|c|}
\hline 1 & Educocä de \\
\hline 2 & \\
\hline 3 & ente era muito comum encontror of \\
\hline 4 & soar analfalretas, sem hirtórico escolor \& com pouco co- \\
\hline 5 & mecimento. Hofs opesor de toda erolução, principalmento \\
\hline 6 & técnuligica, existem pessoas analfobetas e sem excolaridade, \\
\hline 7 & ou seja, a educacäo nöo desfrutor de muition arromeios. \\
\hline 8 & Pon isso, tem sido um desafia a Lociedode, renrenter essa \\
\hline 10 & $\theta^{\prime}$ \\
\hline 10 & afuste nas excolos, seria a implontaçä \\
\hline 12 & Aando una melhon qualidade \\
\hline 13 & 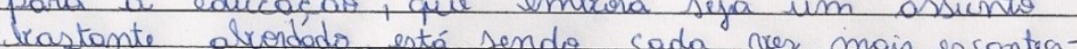 \\
\hline 14 & de pelos politicon e pelos próprion estudontes. As tonces de \\
\hline 15 & ensino fundamental \& seiprrion incomplitos rem caindo \\
\hline 16 & ao longo dos anos borém os alunos tem demonstrado \\
\hline 17 & desinteresse em estudar. \\
\hline 18 & srores tentam tomar inisiatives, fogendo ati- \\
\hline 19 & 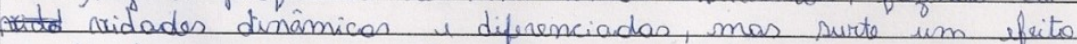 \\
\hline 20 & muito fugaz pois quando os alunos rioltam a sala de \\
\hline 21 & dos a alhar para o quadro e appiar is \\
\hline 22 & \\
\hline 23 & (1) ideal suiar que as escolas encolvissem funtamente com \\
\hline 24 & as outros soias, para assim, propiciar um melhon ensino \\
\hline 25 & entudenter liomiersar com as mesmos a clabionar pro- \\
\hline 26 & afudem a arrecador dinheiro. \\
\hline & \\
\hline
\end{tabular}

Figura 2 - Primeira produção textual

Primeiro texto produzido pelo sujeito de pesquisa, na oficina 02.

Inicialmente, destacamos que o texto apresenta a estrutura de uma dissertação argumentativa, ou seja, possui introdução, desenvolvimento e conclusão. Além disso, está de acordo com a competência 1 - domínio da modalidade escrita formal da Língua Portuguesa. Alguns exemplos disso são: concordância verbal (1. 6 - existem pessoas, 1.18 - professores tentam tomar iniciativas) e translineação (1. 4-5 - conbecimento, 1. 18-19 atividades, 1. 25-26 - projetos). No entanto, existem algumas exceções: problemas de pontuação (1. 5 - Hoje apesar de toda a evolução, 1.8 - tem sido um desafio a sociedade, reverter essa situação, 1.10 - Um ótimo ajuste nas escolas, seria a implantação) e de acentuação (1. 11 tecnologicos, 1.14 - politicos, 1.16 - tem), por exemplo.

Em relação à competência 2 , o tema proposto foi $A$ educação como veículo de mudança na sociedade; porém essa produção textual tem outro viés: os avanços na educação. Na introdução (1. 3-9), a tese defendida é a de que a educação não desfrutou de avanços e o argumento sinalizado é o de que tem sido um desafio para a sociedade superar essa situação. No primeiro parágrafo do desenvolvimento (1. 10-17), há a sugestão para melhoria nas escolas e, também, uma crítica ao descaso dos políticos e desinteresse dos estudantes com a educação. No segundo parágrafo do desenvolvimento (1. 18-22), as iniciativas dos docentes para melhorar esse quadro são ressaltadas. A conclusão (1. 23-26) sugere que as escolas devam evoluir assim como "as outras coisas" e aponta duas soluções: a conversa com os alunos e a elaboração de projetos. 
Além da fuga do tema, o texto possui outras fragilidades, relacionadas às competências 3 e 4, tais como sugestão de solução para o problema antes mesmo de desenvolvê-lo (1. 10-14 - Um ótimo ajuste nas escolas, seria a implantação de recursos tecnologicos visando uma melhor qualidade para a educação, que embora seja um assunto bastante abordado, está cada vez. mais escanteado pelos politicos e pelos próprios estudantes.); argumentação baseada no senso comum, sem argumento de autoridade ou provas concretas, por exemplo (1. 1617 - os alunos tem demonstrado desinteresse em estudar.); exemplificação baseada em uma situação subjetiva e parágrafo contraditório (1. 18-22 - Alguns professores tentam tomar iniciativas, faz̧endo atividades dinâmicas e diferenciadas, mas surte um efeito muito fugaz pois quando os alunos voltam a sala de aula são obrigados a olhar para o quadro e copiar o que estiver escrito.), pois afirma que os professores investem em atividades dinâmicas e, em seguida, destaca que os alunos perdem o interesse nas aulas por terem que copiar conteúdos do quadro; e oração incompleta (1. 25-26 - Conversar com os mesmos e elaborar projetos que ajudem a arrecadar dinheiro.), que prejudica o desenvolvimento da competência 5. O parágrafo contraditório fere a terceira metarregra proposta por Charolles (1978): a metarregra de não contradição, pois introduz um elemento semântico que contradiz o conteúdo posto.

Depois de descrevermos e apontarmos os problemas do texto, passamos, então, a analisar o desenvolvimento da progressão textual. Atentaremos para a progressão referencial. Na introdução, há o uso de ou seja (1. 7), que funciona como introdutor de uma paráfrase (1. 7 - a educação não desfrutou de muitos avanços); Por isso (1. 8) e 1. 8-9 - essa situação, que resumem/encapsulam, respectivamente, 1.7 - a educação não desfrutou de muitos avanços e 1. 5-6 - Hoje apesar de toda a evolução, principalmente tecnológica, existem pessoas analfabetas e sem escolaridade. Os dois parágrafos de desenvolvimento são construídos sem a utilização de formas nominais referenciais. $\mathrm{Na}$ conclusão, os mesmos (1. 25) reapresenta o referente estudantes (1.25).

Cumpre-nos destacar que os outros alunos participantes das oficinas encontraram barreiras iguais ou maiores ao escrever sobre esse tema. Essas dificuldades se devem, possivelmente, à falta de investimento na escrita dos discentes, pois, como foi relatado para a professora/pesquisadora, os alunos haviam produzido apenas uma dissertação no ano.

Então, ao destacarmos tais dificuldades percebidas nesse texto, pretendemos demonstrar que o ensino da produção textual é extremamente importante. É somente com o exercício de produzir textos que as dificuldades são percebidas e os textos passam a ser cada vez mais qualificados. 


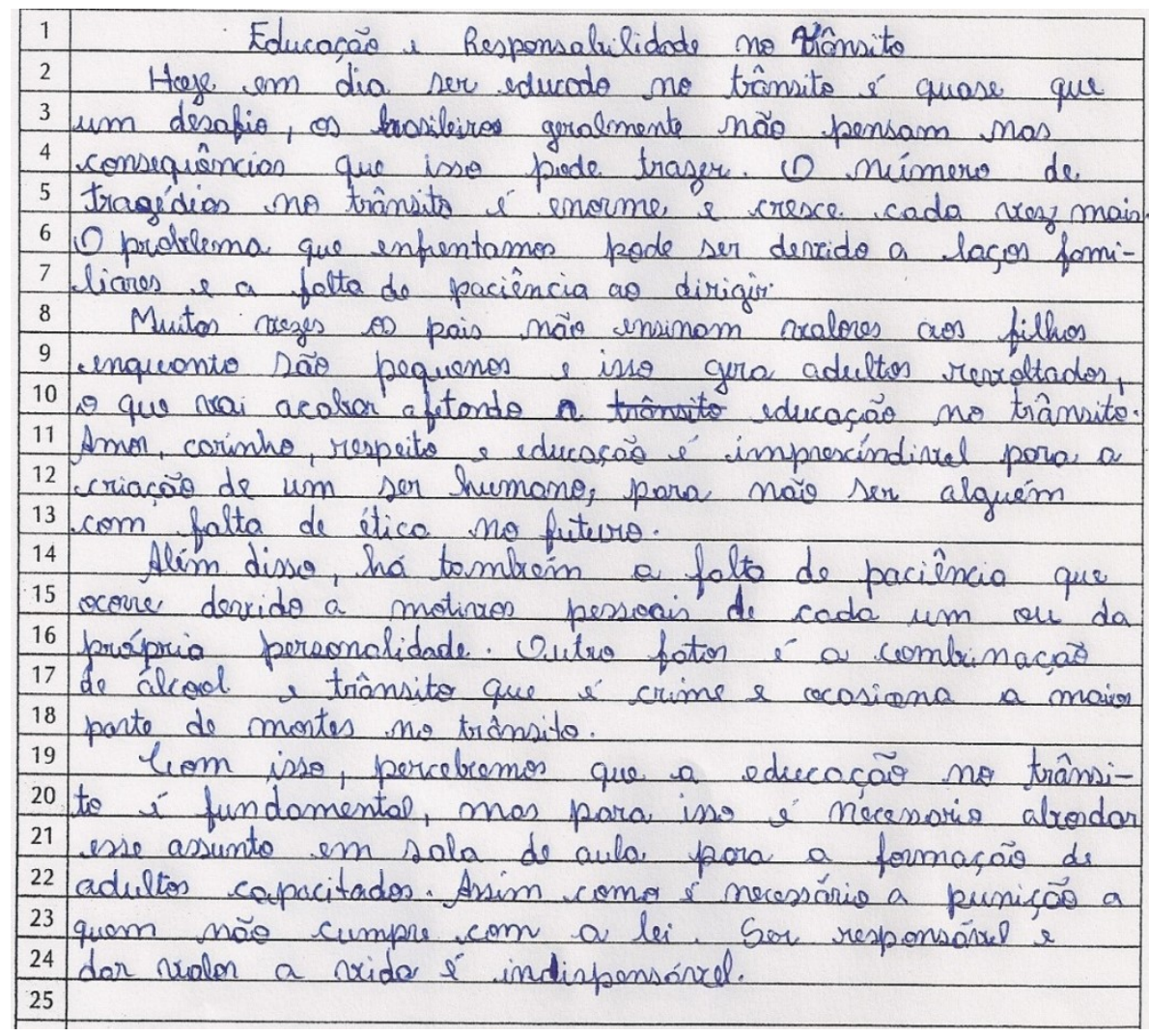

Figura 3 - Terceira Produção Textual

Terceiro texto produzido pelo sujeito de pesquisa, na oficina 06 .

A terceira produção textual, quanto à competência 1, apresenta bom domínio da modalidade escrita formal da Língua Portuguesa e de escolha de registro, com alguns desvios gramaticais e de convenções da escrita. Novamente, problemas de acentuação (1. 7 - a, 1. 20 - necessario), de concordância verbal (1.11 - Amor, carinho, respeito e educação é imprescindivel), de pontuação (1. 2 - Hoje em dia ser educado) e de redundância (1. 15 - motivos pessoais de cada um) são exemplos desses desvios.

A proposta de produção desse texto está baseada no tema $O$ impasse da educação no trânsito no Brasil. O texto segue a estrutura da dissertação-argumentativa. $\mathrm{Na}$ introdução (1. 2-7), há a apresentação do tema e da tese (1. 2-4 - Hoje em dia ser educado no trânsito é quase que um desafio, os brasileiros geralmente não pensam nas consequências que isso pode trazer), e a delimitação dos argumentos que serão defendidos no desenvolvimento (1. 6-7 - O problema que enfrentamos pode ser devido a laços familiares e a falta de paciência ao dirigir).

Esses dois argumentos são defendidos, respectivamente, no primeiro (1. 8-13) e no segundo (1. 14-18) parágrafos do desenvolvimento. A argumentação está baseada apenas nos conhecimentos prévios do sujeito de pesquisa, não apresentando dados, estatísticas ou informações concretas que comprovem o que é afirmado.

Esse problema afeta, também, a avaliação no que diz respeito à competência 3 , pois não há comprovação do que é defendido. Além disso, as propostas de intervenção, presentes na conclusão (1. 20-23 - é necessário abordar esse assunto em sala de aula para a formação de adultos capacitados. Assim como é necessário a punição a quem não cumpre 
com a lei) não estão relacionadas ao restante do texto, ou seja, a coerência está prejudicada. Desse modo, a competência 5 é atendida, mas a competência 3 é afetada.

Quanto à competência 4, ou seja, a estruturação textual, o texto possui alguns conectores, que contribuem para a articulação de ideias (1. 4 - isso retoma 1. 2-3 - ser educado no trânsito é quase que um desafio; 1.6 - o problema remete a 1. 4-5 - O número de tragédias no trânsito é enorme e cresce cada vez mais; 1.9 - isso retoma 1. 8-9 - os pais não ensinam valores aos filhos enquanto são pequenos; 1.14 - Além disso, que retoma o parágrafo anterior (1. 8-13) para acrescentar outro argumento; 1.19 - Com isso, que retoma o que foi exposto no texto e indica conclusão de ideias; 1.20 - para isso retoma 1. 19-20 a educação no trânsito é fundamental; e 1. 22 Assim como, que acrescenta a segunda proposta de intervenção).

Dessa forma, quanto à análise da progressão textual, percebemos que o texto progride com o auxílio dessas expressões. A progressão referencial está presente em vários trechos. Novamente, a reapresentação do referente à medida que o texto avança é um dos casos mais comuns (1. 4 e 1.9 - isso reapresenta, respectivamente, 1. 2-3 - ser educado no trânsito é quase que um desafio e 1. 8-9 - os pais não ensinam valores aos filhos enquanto são pequenos). Outra expressão nominal que merece atenção é O problema (1. 6), que, além de encapsular $O$ número de tragédias no trânsito é enorme e cresce cada veź mais (1. 4-5), orienta argumentativamente o leitor com a opinião negativa em relação ao crescimento do número de tragédias no trânsito. O encapsulamento de uma porção textual é perceptível, também, em Outro fator (1. 16), que encapsula a falta de paciência (1. 14), e, ao mesmo tempo, possibilita a apresentação do segundo argumento do parágrafo. Ademais, a organização do texto ocorre pelo uso de articuladores textuais: 1.14 - Além disso; 1.19 - Com isso; e 1. 22 - Assim como. 


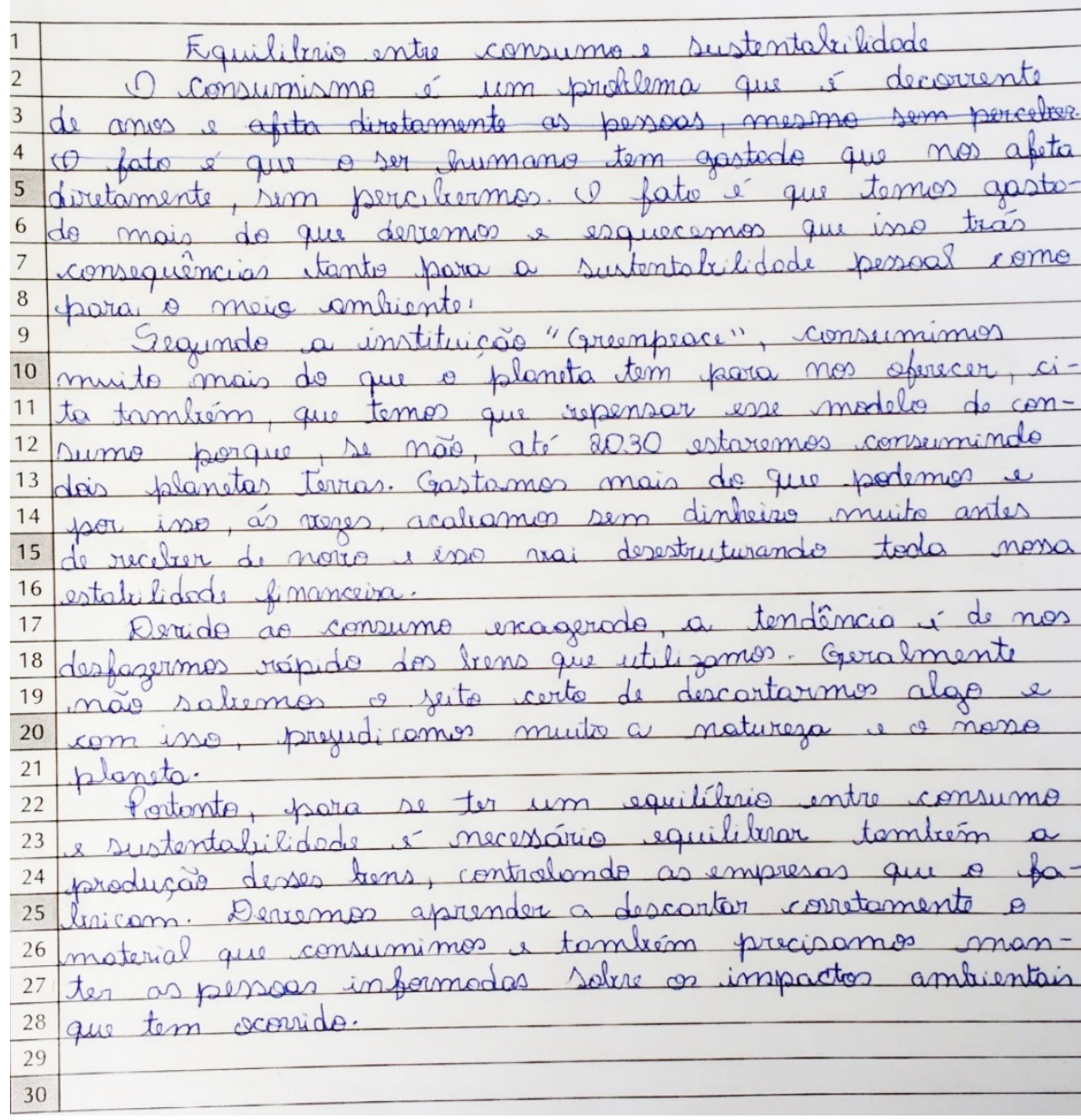

Figura 4 - Quinta produção textual

Quinto texto produzido pelo sujeito de pesquisa, na oficina 10.

No último texto que compõe o corpus de nossa análise, quanto à competência 1, há bom domínio da modalidade escrita formal da Língua Portuguesa e de escolha de registro, com alguns desvios gramaticais e de convenções da escrita. Tais desvios são relativos à grafia (1. 6 - trás); acentuação (1. 1 - Equilibrio e 1.14 - ás); pontuação (1. 22-23 - para se ter um equilíbrio entre consumo e sustentabilidade é necessário); e concordância nominal $(1.24-0)$. Devemos salientar que alguns desses desvios podem sinalizar desatenção ou falta de revisão textual, visto que é perceptível, por exemplo, que equilíbrio (1.22) foi acentuado corretamente e que a vírgula foi empregada para demarcar o deslocamento do adjunto adverbial em Segundo a instituição 'Greenpeace', (1. 9), o que não acontece no caso de falta desse emprego da vírgula no exemplo de pontuação, citado acima.

A proposta de redação foi atendida, o que compreende a competência 2. O tema solicitado foi $O$ desequilíbrio entre consumo e sustentabilidade. $\mathrm{Na}$ introdução (1. 2-8), o tema é apresentado (1. 2-5 - O consumismo é um problema que é decorrente de anos e que nos afeta diretamente, sem percebermos). A tese é demarcada em (1. 5-8 - O fato é que temos gastado mais do que devemos e esquecemos que isso trás consequências tanto para a sustentabilidade pessoal como para o meio ambiente). Nesse trecho, encontramos também a sinalização dos dois argumentos que serão defendidos: problemas para a sustentabilidade e para o meio ambiente. 
O primeiro parágrafo do desenvolvimento (1. 9-16) traz informações sobre o consumo excessivo da população, com a citação da fonte Greenpeace. Entretanto, o parágrafo que começa informativo, termina com a exposição de um conhecimento de mundo do autor e de forma narrativa (1. 13-16 - ás vezes, acabamos sem dinheiro muito antes de receber de novo e isso vai desestruturando toda nossa estabilidade financeira). Esse relato não é característico de uma dissertação argumentativa e afeta a avaliação de parte da competência 2 .

O segundo parágrafo do desenvolvimento (1. 17-21) afirma que o consumo exagerado traz prejuízos à natureza. Contudo, a argumentação baseia-se apenas nos conhecimentos prévios do autor do texto, novamente. Dessa forma, quanto à competência 3, notamos que houve um avanço na construção da argumentação com a citação da fonte Greenpeace, mas o restante do desenvolvimento seguiu o senso comum.

A conclusão (1. 22-28), além de retomar o tema (1. 22-23 - para se ter um equilíbrio entre consumo e sustentabilidade), apresenta propostas de intervenção para o problema muito significativas: equilíbrio da produção dos bens, controle das empresas fabricantes, descarte correto de bens e informação sobre os impactos ambientais. Assim, quanto à competência 5, há boa elaboração da proposta de intervenção, relacionada ao tema e articulada à discussão desenvolvida no texto.

A competência 4 relativa a esse texto obteve avanços, já que há demonstração de maior conhecimento de mecanismos linguísticos se compararmos com a quarta produção. Há o emprego, por exemplo, de encadeadores textuais que orientam a argumentação (1. 7 - tanto ... como, 1. 9 - Segundo, 1. 22 - Portanto). Ademais, indicam referenciação os seguintes vocábulos: $(1.6$ e 15 - isso, 1.11 - esse, 1.14 - por isso, 1.20 com isso, 1.24 - desses, 1. 24-o). Indicaremos os referentes desses termos com o seguinte quadro:

Quadro 2 - A progressão referencial na quinta produção textual.

\begin{tabular}{|c|c|c|c|}
\hline Linba & Termo que refere & Referente & Função da forma nominal referencial \\
\hline 6 & isso & $\begin{array}{l}\text { Temos gastado mais do que devemos } \\
(\text { (. 5-6) }\end{array}$ & Resumo de porção textual \\
\hline 11 & $\begin{array}{l}\text { esse modelo } \\
\text { de consumo }\end{array}$ & $\begin{array}{l}\text { Consumimos muito mais do que o } \\
\text { planeta tem para nos oferecer }(\text { l. } 9-10)\end{array}$ & $\begin{array}{l}\text { Resumo de porção textual, } \\
\text { dando-lhe um rótulo }\end{array}$ \\
\hline 14 & por isso & Gastamos mais do que podemos (l. 13) & Resumo de porção textual \\
\hline 15 & isso & $\begin{array}{l}\text { Acabamos sem dinheiro muito antes de } \\
\text { receber de novo (l. 14) }\end{array}$ & Resumo de porção textual \\
\hline 20 & isso & $\begin{array}{l}\text { Não sabemos o jeito certo de } \\
\text { descartarmos algo (l. 19) }\end{array}$ & Resumo de porção textual \\
\hline 24 & desses & Dos bens que utilizamos (l.18) & Resumo de porção textual \\
\hline 24 & o & Desses bens & Reapresentação do referente \\
\hline
\end{tabular}


Como observamos no quadro 2 , a progressão referencial ocorre com o emprego das funções das formas nominais referenciais resumo de porção textual (com ou sem rótulo) e a reapresentação do referente.

Dessa forma, sobre a progressão referencial, houve o uso de: introdutores de paráfrase e de expressões nominais referenciais que resumem, encapsulam e, até mesmo, orientam argumentativamente. Novamente, o avanço na argumentação certamente propiciaria maior variedade de expressões nominais referenciais, o que qualificaria a progressão referencial.

\section{CONSIDERAÇÕES FINAIS}

Procuramos analisar o processo de qualificação da produção textual escrita, especificamente a partir das marcas linguísticas que envolvem a progressão textual, mais especificamente a progressão referencial. Ao final deste texto, dois pontos podem ser destacados, que envolvem tanto questões de ordem interacional quanto textual.

O primeiro ponto está relacionado à contribuição da pesquisa-ação tanto na formação discente quanto na formação docente. Notamos que a troca de conhecimentos entre professor-aluno e aluno-aluno foi benéfica para a compreensão do que estava sendo trabalhado nas oficinas de produção de texto. Além disso, a interação entre os alunos no momento de produção foi extremamente válida para o compartilhamento de conhecimentos linguístico-textuais.

O segundo ponto diz respeito ao estudo da progressão textual, já que os discentes voluntários da pesquisa não conheciam e não haviam estudado tal estratégia de construção de texto. Assim, como acompanhamos a produção dos discentes, o desenvolvimento da escrita quanto a esse tópico foi qualificado. Os discentes participantes da pesquisa possuíam grandes dificuldades para escrever. Essas dificuldades atrelavam-se a vários âmbitos: pouco conhecimento do tema solicitado na proposta de redação; pouco conhecimento da estrutura de uma dissertação argumentativa, do reconhecimento do tema e dos argumentos, por exemplo; dificuldade para planejar a argumentação, com recorrente uso de conhecimentos prévios e emprego de senso comum; e dificuldades para encadear ideias/argumentos.

Diante disso, confirmamos a hipótese de nossa pesquisa. Ao analisarmos a progressão em textos escritos, procuramos, de certa maneira, entender o processo maior, mais amplo, que envolve a produção interacional do texto e os arranjos locais e concretos da escrituralidade. Tentamos mostrar que produzir um texto, portanto, envolve questões de várias ordens, que se conectam de maneira indissociável às questões sociointeracionais, as quais, por seu turno, são configuradas pela ordem textual instaurada.

\section{REFERÊNCIAS}

Bakhtin MM. Marxismo e filosofia da linguagem: problemas fundamentais do método sociológico da linguagem. 16. a ed. São Paulo: Hucitec; 2014.

- Para uma filosofia do ato. Trad. Carlos Alberto Faraco e Cristóvão Tezza (tradução não revisada, exclusiva para uso didático e acadêmico) da edição americana Toward a Philosophy of the Act. Austin: University of Texas Press; 1993. 
. Estética da criação verbal. Trad. Maria Hermentina Galvão G. Pereira. 2. ${ }^{a}$ ed. São Paulo:

Martins Fontes; 1997.

Beaugrande R, Dressler W. Introduction to Text Linguistic. London: Longman; 1983.

Bentes AC, Ramos P, Alves Filho F. Enfrentando desafios no campo dos estudos do texto. In: Bentes AC, Leite MQ. Linguística de texto e análise da conversação: panoramas das pesquisas no Brasil; 2010. p. 389-428.

Brasil. A redação do Enem 2013: guia do participante. Brasília; 2013.

Charolles M. Coherence as a principle and text interpretation of discourse. Amsterdan: Mouton Publishers; 1978.

Fuzer C. Bilhete orientador como instrumento de interação no processo ensino-aprendizagem de produção textual. Letras (UFSM). jan./jun. 2012;22(44):213-245.

Groos PT. A qualificação da progressão textual em oficinas de produção de texto [dissertação]. Santa Maria: Programa de Pós-graduação em Letras, Universidade Federal de Santa Maria; 2017.

Koch IV. A inter-ação pela linguagem. 10. ${ }^{a}$ ed. São Paulo: Contexto; 2006.

As tramas do texto. 2. ${ }^{a}$ ed. São Paulo: Contexto; 2014.

. Desvendando os segredos do texto. São Paulo: Cortez; 2003; 2006.

Introdução à Linguística textual: trajetória e grandes temas. 2. ${ }^{a}$ ed. São Paulo; 2015.

. O texto e a construção dos sentidos. São Paulo: Contexto; 1997.

; Elias VM. Ler e compreender: os sentidos do texto. São Paulo: Contexto; 2006; 2008.

. Escrever e argumentar. São Paulo: Contexto; 2016.

Micarello HALS, Magalhães TG. Letramento, linguagem e escola. Bakhtiniana. ago./dez. 2014;9(2):150-163.

Perrenoud P. A prática reflexiva no ofício do professor: profissionalização e razão pedagógicas. Porto Alegre: Artmed Editora; 2002.

Ruiz EMSD. Como se corrige redação na escola. Campinas: Mercado das Letras; 2001.

Thiollent M. Metodologia da pesquisa-ação. São Paulo: Cortez; 1996.

Tripp D. Pesquisa-ação: uma introdução metodológica. Educação e Pesquisa. 2005;31(3):443-466.

Vygotsky LS. A formação social da mente. São Paulo: Martins Fontes; 1984.

. Pensamento e linguagem. São Paulo: Martins Fontes; 1991. 